\title{
Sex differences in the association between green tea consumption and hypertension in elderly Chinese adults
}

Xiaodong Peng ${ }^{1,2}$, Mengxia Zhang ${ }^{1,2}$, Xuesi Wang ${ }^{1,2}, K^{\prime} \mathrm{Wu}^{1,2}$, Yukun $\mathrm{Li}^{1,2}$, Linling $\mathrm{Li}^{3}$, Jiaxue Yang ${ }^{1,2}$, Yanfei Ruan ${ }^{1,2}$, Rong Bai ${ }^{1,2}$, Changsheng Ma ${ }^{1,2}$ and Nian Liu ${ }^{1,2^{*}}$

\begin{abstract}
Background: Green tea has been one of the most popular beverages in China since ancient times. Mixed results concerning the effect of green tea consumption on the incidence of hypertension have been published over the past decades. However, no previous studies have focused on longevous individuals in China and the sex differences in the association between habitual green tea intake and hypertension.

Methods: The data extracted from the database of the Chinese Longitudinal Healthy Longevity Survey (CLHLS) in 2018 were used for a secondary analysis. Logistic regression models were employed to examine the odds ratio (OR) of daily green tea consumption on the incidence of hypertension by sex.

Results: A total of 9277 individuals were included in the analysis (39.8\% were men). The included individuals had a mean age of 80.9 and 84.8 years for those who drank green tea daily and those who had never, respectively $(p<0.001)$. The incidence of hypertension varied at baseline according to green tea drinking habit and sex. For women who had a habitual green tea intake or had never drunk green tea, the incidence of hypertension was 47.3 and $43.9 \%$, respectively $(p=0.241)$, whereas it was 51.6 and $39.7 \%$ for men $(p<0.001)$. After adjusting for potential confounders, a $38 \%$ increase in the risk of hypertension was observed in men who consumed green tea daily (OR, $1.38 ; 95 \% \mathrm{Cl}, 1.15-1.67 ; p<0.001)$.

Conclusions: Chinese longevous men had a 38\% higher risk of developing hypertension when drinking green tea daily. However, no effect of green tea consumption on the incidence of hypertension in women was found. More attention should be paid to the lifestyle of longevous individuals for health promotion, and a sex-specific approach to deliver care for very elderly people is warranted.
\end{abstract}

Keywords: Sex difference, Green tea, Tea, Blood pressure, Hypertension, Elderly, China

\section{Background}

Green tea is one of the most popular beverages in China, and has attracted the attention of elderly Chinese people given the belief that drinking green tea regularly could

\footnotetext{
* Correspondence: liunian1973@hotmail.com

'Department of Cardiology, Beijing Anzhen Hospital, Capital Medical University, Beijing, China

${ }^{2}$ National Clinical Research Center for Cardiovascular Diseases, Beijing, China Full list of author information is available at the end of the article
}

benefit hypertension. Indeed, some clinical and fundamental studies have indicated that green tea can reduce blood pressure in patients with hypertension. A previous meta-analysis emphasized the hypotensive effect of green tea by demonstrating that it contributed to a decrease in systolic and diastolic blood pressure by $4.81 \mathrm{mmHg}$ and $1.98 \mathrm{mmHg}$, respectively [1]. Green tea is the most abundant catechin (polyphenol epigallocatechin-3-gallate [EGCG]), which exerts anti-inflammatory and

(C) The Author(s). 2021 Open Access This article is licensed under a Creative Commons Attribution 4.0 International License, which permits use, sharing, adaptation, distribution and reproduction in any medium or format, as long as you give appropriate credit to the original author(s) and the source, provide a link to the Creative Commons licence, and indicate if changes were made. The images or other third party material in this article are included in the article's Creative Commons licence, unless indicated otherwise in a credit line to the material. If material is not included in the article's Creative Commons licence and your intended use is not permitted by statutory regulation or exceeds the permitted use, you will need to obtain permission directly from the copyright holder. To view a copy of this licence, visit http://creativecommons.org/licenses/by/4.0/. The Creative Commons Public Domain Dedication waiver (http://creativecommons.org/publicdomain/zero/1.0/) applies to the data made available in this article, unless otherwise stated in a credit line to the data. 
antioxidant effects to reduce elevated blood pressure [2]. However, the results remain controversial as some investigators found no association between green tea consumption and blood pressure [3].

Importantly, sex differences should also be taken into consideration, as the relationship between beverage consumption and the risk of hypertension varies by sex [4]. Over the past decades, it has been proven that females are more vulnerable to several pathological conditions, especially cardiovascular diseases [5]. Moreover, women are also more likely to receive a less effective treatment, leading to a worse clinical outcome [6]. Estrogen is regarded as a protective factor for hypertension, which may partly liberate women from hypertension at an early age [7]. However, the incidence of hypertension is higher in women aged $>60$ years than in men, although it is less likely for females to maintain hypertension control [8]. Thus, it is imperative to effectively manage blood pressure using sex-specific approaches.

Therefore, in the current study, we sought to explore the sex difference in the relationship between green tea consumption and hypertension in the Chinese elderly population.

\section{Methods}

\section{Study population}

The information of this cohort study was obtained from the dataset of the seventh wave of the Chinese Longitudinal Healthy Longevity Survey (CLHLS) in 2018. A detailed description of the study design has been reported previously [9]. A total of 15,874 elderly participants from 23 out of 31 provinces in China were enrolled in this survey, and 12,411 of them were interviewed in 2018. Among the samples, the proportion of the population with advanced age ( $\geq 80$ years) was $67.4 \%$. A standard questionnaire was administered by well-trained practitioners to collect items of interest, including sociodemographic, lifestyle, and disease-related information. The CLHLS study was approved by the Biomedical Ethics Committee of the Peking University. All participants provided written informed consent. The study was conducted according to the Strengthening the Reporting of Observational Studies in Epidemiology (STROBE) reporting guidelines [10].

\section{Data collection}

A face-to-face interview was conducted to complete a questionnaire containing various types of information. Demographic data, including age, sex, residence, and marital status, were recorded. The health-related information reported by participants and lifestyle factors were collected, which included self-reported hypertension (systolic blood pressure $\geq 140 \mathrm{mmHg}$ and/or diastolic blood pressure $\geq 90 \mathrm{mmHg}$ ), diabetes, dyslipidemia, heart diseases, stroke or cerebrovascular diseases (CVD), smoking status, drinking status, and dietary habits. Subsequently, the database was screened to exclude samples with unavailable data. The inclusion criteria were as follows: (1) advanced age of $\geq 65$ years; (2) reported the frequency of green tea drinking at present and in the past; (3) described the types of tea that they normally drink; and (4) whether they have hypertension or not. Some important information, such as body mass index (BMI) and educational level of participants, which has been previously proven to be associated with hypertension, was ineligible for this study because numerous data derived from the database were invalid $[11,12]$.

\section{Specific definition}

The frequency of green tea consumption was defined as "daily" or "never". Based on the content of the questionnaire applied in the CLHLS program, a daily green tea drinker regularly had regularly consumed green tea since they were at least 60 years old without discontinuity ( $\geq$ 5 years). The living location was classified as northern and southern China, which was separated by the Qinling Mountains-Huaihe River line. Cities such as Beijing and Tianjin belong to northern China, whereas provinces such as Hunan and Guangdong are considered to be in southern China. Marital status included married individuals and others. The participants who were currently married and living with or separated from their spouse were defined as married, while the others represented those who were divorced, widowed, or never married. Smoking status was also recorded, and two important timelines (the present and when the participants were 60 years old) were set to distinguish the current (smokers at both timelines), the former (not smokers at present), and never smokers (never smoked). These two timelines were applied to identify whether the participants had a daily diet of fresh vegetables, fruits, or salted preserved vegetables. Self-reported physician-diagnosed medical conditions, including hypertension, diabetes, dyslipidemia, heart diseases, stroke, and cerebrovascular diseases were collected.

The mental symptoms of anxiety were measured using the generalized anxiety disorder (GAD-7) form [13]. The GAD-7 form includes seven questions: (1) "Feeling uneasy, worried, and annoyed?"; (2) "Cannot stop worrying?"; (3) "Worry too much about various things?"; (4) "Too nervous to relax?"; (5) "too anxious to sit still?"; (6) "Easily annoyed or irritated?"; and (7) "Feeling like something terrible will happen." The score of a single symptom varies from 0 (never) to 3 (almost every day), and the total score ranges from 0 to 21 . Elevated symptoms of anxiety were defined when the total score was $\geq 5$ [13]. Other covariates, such as number of hours of sleep, 
having a pension, drinking daily, and regular physical labor, were extracted from the questionnaire.

\section{Statistical analysis}

The baseline characteristics are described according to sex and the frequency of green tea consumption. Continuous data are presented as the mean \pm standard deviation (SD), and categorical data are presented as frequency with percentage, which were analyzed with one-way ANOVA and chi-square test, respectively.

To further investigate the association between daily green tea consumption and the incidence of hypertension, multivariate logistic regression was performed to calculate odds ratios (ORs) with 95\% confidence intervals (CIs). Three models based on sex differences were used to adjust for the influence of covariates. Age was adjusted in model 1. Urban residence, living location, pension, marital status, smoking status, sleep hours and eating salt-preserved vegetables daily were adjusted in model 2. All covariates, including comorbid diabetes and dyslipidemia were adjusted in model 3. Sex was added to the model for the overall estimation. In logistic regression analysis, all data were presented as categorical variables. Age was classified into $<80$ years old and $\geq 80$ years old, while sleep hours were separated into $<6,6-8$, and $>8 \mathrm{~h}$.

Subsequently, subgroup analyses were performed to test the potential influence of sociodemographic and health-related factors, including age, residence, living location, marital status, pension, smoking status, sleep hours (divided into $<6 \mathrm{~h}, 6-8 \mathrm{~h}$, and $>8 \mathrm{~h}$ ), comorbid diseases (diabetes and dyslipidemia), and dietary habits (eating salt-preserved vegetables daily). The $P$-value for interaction was assessed by likelihood ratio tests, and all statistical analyses were performed using SPSS software (version 19.0; IBM Corporation, Armonk, NY, USA).

\section{Results}

Of the 15,874 participants, 11,509 were included after excluding individuals aged $<65$ years, and those with no record of the frequency of tea drinking, types of tea drinking, and history of hypertension. Finally, a total of 9277 participants who had never drank green tea or had drunk green tea daily were enrolled in this study. The baseline characteristics of the enrolled participants are presented in Table 1. For women, the average age was 84.0 years $(\mathrm{SD}=12.0)$ and 87.7 years $(\mathrm{SD}=12.1)$ in those who did and did not drink green tea, respectively. Men were younger than women, with a mean age of 80.9 years $(\mathrm{SD}=10.6)$ for daily green tea drinkers and 84.8 years $(\mathrm{SD}=11.1)$ for those who had never consumed green tea. Approximately $39.0 \%$ of women lived in urban areas, while men who never drank green tea usually lived in rural areas $(73.0 \%)$. The majority of the participants came from southern China ( $>70 \%)$. Women were more likely to be divorced, widowed, or never married (< $30 \%$ ), whereas more than $50 \%$ of the men were married. The individuals who had never drank green tea tended to perform labor work regularly $(73.2 \%$ vs. $66.1 \%$ for women, $p<0.05$, and $75.2 \%$ vs. $64.7 \%$ for men, $p<0.001)$. It seemed that the women were also less wealthy than the men, as the proportion of women with a pension was obviously lower than that of men. Moreover, over $90 \%$ of women never smoked, while current smokers were more common in men $(38.3 \%$ vs. $23.8 \%$ for daily green tea drinking and never green tea drinking, respectively, $p<0.001$ ). Current alcohol use was more common in men and daily green tea drinkers.

Compared to women who did not drink green tea, those who drank green tea daily were more likely to have comorbid diabetes $(14.8 \%$ vs. $9.3, p<0.05)$, dyslipidemia $(11.4 \%$ vs. $4.6 \%, p<0.001)$, and heart diseases $(25.2 \%$ vs. $17.6 \%, p<0.05)$. No significant difference was found in women with regard to the incidence of hypertension, dietary habits, anxiety scores, and sleep hours. The incidence of hypertension was remarkably higher in men who drank green tea daily $(51.6 \%$ vs. $39.7 \%, p<0.001)$. In addition, a history of diabetes $(14.1 \%$ vs. $8.3 \%$, $p<0.001)$, dyslipidemia ( $7.9 \%$ vs. $4.1 \%, p<0.001)$, and heart disease $(18.6 \%$ vs. $15.1 \%, p<0.05)$, and the dietary habits of eating fresh vegetables $(73.6 \%$ vs. $62.5 \%$, $p<0.001)$ and fruits $(26.9 \%$ vs. $20.4 \%, p<0.001)$ were more prevalent in men.

Women were not associated with a higher risk of hypertension according to the frequency of green tea consumption (Fig. 1). On the contrary, after adjusting for potential risk factors (model 3 ), the daily consumption of green tea increased the incidence of hypertension by $38 \%$ (95\% CI: $1.15-1.67, p<0.001)$ in men (Table 2 ). Similarly, the effect of green tea consumption on the incidence of hypertension was detrimental but not significant in the general population (OR, 1.16; 95\% CI, 1.00$1.37, p=0.057$ ).

The relationship between green tea consumption and hypertension was stratified by potential confounding factors (Fig. 2). For women, those who lived in the urban area seemed to be more vulnerable to hypertension (adjusted OR, 1.30; 95\% CI, 0.84-2.02) compared to those in the rural area (adjusted OR, 0.73; 95\% CI, 0.53-1.00) $(p<0.05)$. For men, the results did not significantly change after adjusting for age, urban residence, living location, marital status, pension, smoking status, sleep duration, eating salt-preserved vegetables daily, and comorbid diabetes and hyperlipidemia.

\section{Discussion}

In this study, including 9277 individuals of advanced age, men drinking green tea daily (at baseline) were 
Table 1 Baseline characteristics of the participants by sex

\begin{tabular}{|c|c|c|c|c|c|c|}
\hline \multirow[t]{2}{*}{ Characteristics } & \multicolumn{3}{|l|}{ Women } & \multicolumn{3}{|l|}{ Men } \\
\hline & $\begin{array}{l}\text { Green tea daily } \\
(n=298)\end{array}$ & $\begin{array}{l}\text { Green tea never } \\
(n=5343)\end{array}$ & $P$-value & $\begin{array}{l}\text { Green tea daily } \\
(n=624)\end{array}$ & $\begin{array}{l}\text { Green tea never } \\
(n=3012)\end{array}$ & $P$-value \\
\hline Age, mean (SD), y & $84.0(12.0)$ & $87.7(12.1)$ & $<0.001$ & $80.9(10.6)$ & $84.8(11.1)$ & $<0.001$ \\
\hline Urban residence, n (\%) & $116(38.9)$ & $2107(39.4)$ & 0.861 & $279(44.7)$ & $812(27.0)$ & $<0.001$ \\
\hline \multicolumn{7}{|l|}{ Area, n (\%) } \\
\hline Northern China & $48(16.1)$ & $1587(29.7)$ & $<0.001$ & $149(23.9)$ & $893(29.6)$ & 0.004 \\
\hline Southern China & $250(83.9)$ & $3756(70.3)$ & & $475(76.1)$ & $2119(70.4)$ & \\
\hline Married, n (\%) & $114(38.3)$ & $1447(27.1)$ & $<0.001$ & $432(69.2)$ & $1633(54.2)$ & $<0.001$ \\
\hline Physical labor regularly, n (\%) & $197(66.1)$ & $3910(73.2)$ & 0.008 & $404(64.7)$ & $2265(75.2)$ & $<0.001$ \\
\hline Having pension, n (\%) & $103(34.6)$ & $842(15.8)$ & $<0.001$ & $288(46.2)$ & $787(50.7)$ & 0.040 \\
\hline \multicolumn{7}{|l|}{ Smoking status, n (\%) } \\
\hline Never smoker & $270(90.6)$ & $4969(93.0)$ & 0.205 & $187(30.0)$ & $1526(50.7)$ & $<0.001$ \\
\hline Former smoker & $13(4.4)$ & $201(3.8)$ & & $198(31.7)$ & $770(25.6)$ & \\
\hline Current smoker & $15(5.0)$ & $173(3.2)$ & & $239(38.3)$ & $716(23.8)$ & \\
\hline Current drinking, n (\%) & $32(10.7)$ & $264(4.9)$ & $<0.001$ & $209(33.5)$ & $629(20.9)$ & $<0.001$ \\
\hline Sleeping time, mean (SD), h & $7.2(2.4)$ & $7.4(2.5)$ & 0.170 & $7.5(2.0)$ & $7.7(2.3)$ & 0.076 \\
\hline \multicolumn{7}{|l|}{ Anxiety score, n (\%) } \\
\hline $0-4$ & $263(88.3)$ & $4657(87.2)$ & 0.582 & $579(92.8)$ & $2730(90.6)$ & 0.087 \\
\hline$\geq 5$ & $35(11.7)$ & $686(12.8)$ & & $45(7.2)$ & $282(9.4)$ & \\
\hline \multicolumn{7}{|l|}{ History of comorbidities, n (\%) } \\
\hline Hypertension & $141(47.3)$ & $2343(43.9)$ & 0.241 & $322(51.6)$ & $1197(39.7)$ & $<0.001$ \\
\hline Diabetes & $44(14.8)$ & $497(9.3)$ & 0.002 & $88(14.1)$ & $249(8.3)$ & $<0.001$ \\
\hline Dyslipidemia & $34(11.4)$ & $244(4.6)$ & $<0.001$ & $49(7.9)$ & $122(4.1)$ & $<0.001$ \\
\hline Heart diseases & $75(25.2)$ & 938 (17.6) & 0.001 & $116(18.6)$ & $456(15.1)$ & 0.031 \\
\hline Stroke or CVD & $40(13.4)$ & $530(9.9)$ & 0.051 & $78(12.5)$ & $394(13.1)$ & 0.694 \\
\hline Eating fresh vegetables daily, n (\%) & $200(67.1)$ & $3357(62.8)$ & 0.136 & $459(73.6)$ & $1882(62.5)$ & $<0.001$ \\
\hline Eating salt-preserved vegetables daily, n (\%) & $47(15.8)$ & $722(13.5)$ & 0.269 & $76(12.2)$ & $329(10.9)$ & 0.364 \\
\hline Eating fresh fruits daily, $\mathrm{n}(\%)$ & $74(24.8)$ & $1157(21.7)$ & 0.196 & $168(26.9)$ & $614(20.4)$ & $<0.001$ \\
\hline
\end{tabular}

more likely to have comorbid hypertension compared to those who did not drink green tea (51.6\% vs. 39.7\%). After adjusting for potential confounders, a 38\% increase in the risk of developing hypertension among elderly men who enjoyed green tea was estimated. The main finding reflected an interesting fact that green tea consumption may increase $38 \%$ the risk of developing hypertension in elderly men from China, whereas no impact of such habits on the incidence of hypertension in women was observed.

The results of studies aiming to investigate the effect of green tea on the risk of hypertension have been mixed. Although a large number of studies have pointed out that it is beneficial for healthy individuals to take green tea as a daily beverage $[1,14,15]$, others have found the opposite $[3,16]$. One possible explanation is the different compounds that are extracted from green tea, such as caffeine, which is considered to significantly increase the risk of hypertension. A study from Singapore showed that green tea is related to a higher incidence of hypertension, but the risk was attenuated to be non-significant after adjusting for caffeine [16]. In contrast, polyphenols extracted from green tea are believed to be protective in preventing hypertension [17]. Interestingly, different processes of preparing a cup of green tea may lead to a significant difference in the concentrations of caffeine and polyphenols [18]. For example, young tea leaves often contain more caffeine and less polyphenols. Moreover, the biological function of green tea may be stronger when dissolved in $75 \%$ ethanol rather than boiling water. Under the condition of higher concentrations of caffeine, tea may have a detrimental impact on the cardiovascular system, contributing to a modest increase in systolic and diastolic blood pressure, bradycardia or tachycardia, and stimulating the release of some neuroendocrine hormones [18]. These 


\section{Women}

a.

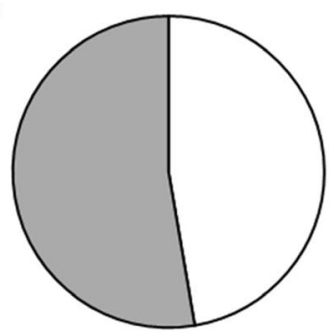

Drinking green tea daily

Men

c.

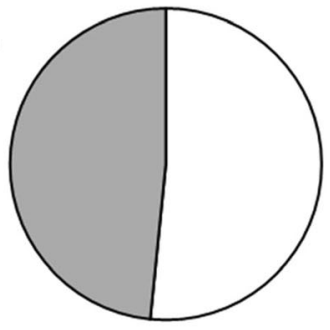

Drinking green tea daily b.

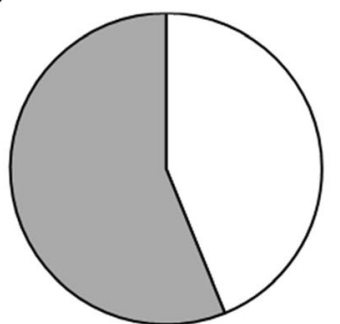

Drinking green tea never

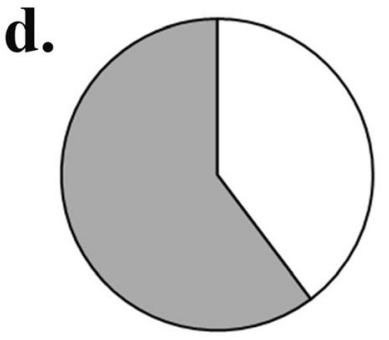

Drinking green tea never

Fig. 1 Incidence of hypertension according to green tea drinking habit and sex. The pie charts show the prevalence of hypertension: the white part represents individuals with hypertension while the grey part represents individuals without

dose-dependent effects emphasize the importance of the optimal dosage for green tea intake, which requires further investigation.

Although the hypothesis that green tea could benefit patients with hypertension has been discussed over the past decades, little is known about the effect on very elderly individuals aged $\geq 80$ years. This study found that the overall prevalence of hypertension in the elderly was $43.1 \%$, which was lower than that in adults aged $\geq 80$ years and older (76.5\%) [19]. Therefore, it reflected a better state of health of the participants from the CLHLS database, which could

Table 2 Association between habitual green tea drinking and risk of hypertension by sex

\begin{tabular}{|c|c|c|c|c|c|}
\hline & \multirow{2}{*}{$\begin{array}{l}\text { Participants, } \\
\text { No. }\end{array}$} & \multirow{2}{*}{$\begin{array}{l}\text { Prevalence of } \\
\text { hypertension } \\
\text { No. (\%) }\end{array}$} & \multicolumn{3}{|l|}{ OR $(95 \% \mathrm{Cl})$} \\
\hline & & & Model $1^{\mathrm{a}}$ & Model $2^{b}$ & Model $3^{c}$ \\
\hline \multicolumn{6}{|l|}{ Overall } \\
\hline Never drinker & 8355 & $3540(42.5)$ & Reference & Reference & Reference \\
\hline Daily drinker & 922 & $463(50.2)$ & $1.37(1.19-1.58)^{* *}$ & $1.20(1.04-1.39)^{*}$ & $1.16(1.00-1.35)$ \\
\hline \multicolumn{6}{|l|}{ Women $^{d}$} \\
\hline Never drinker & 5343 & $2343(43.9)$ & Reference & Reference & Reference \\
\hline Daily drinker & 298 & $141(47.3)$ & $1.10(0.87-1.39)$ & $0.93(0.73-1.18)$ & $0.88(0.69-1.14)$ \\
\hline \multicolumn{6}{|l|}{ Men $^{d}$} \\
\hline Never drinker & 3012 & 1197 (39.7) & Reference & Reference & Reference \\
\hline Daily drinker & 624 & $322(51.6)$ & $1.58(1.33-1.88)^{* *}$ & $1.43(1.19-1.71)^{* *}$ & $1.38(1.15-1.67)^{* *}$ \\
\hline
\end{tabular}

OR Odds ratio. *Statistically significant difference $(p<0.05),{ }^{*}$ statistically significant difference $(p<0.001)$

${ }^{\text {a }}$ Model 1 was adjusted for age and sex

${ }^{\mathrm{b}}$ Model 2 was adjusted for Model 1 + urban residence, living location, marital status, pension, smoking status, sleep duration, and eating salt-preserved vegetables daily

"Model 3 was adjusted for Model $2+$ comorbid diabetes and hyperlipidemia

${ }^{\mathrm{d}}$ Model 1-3 used for women and men excluded the sex category 


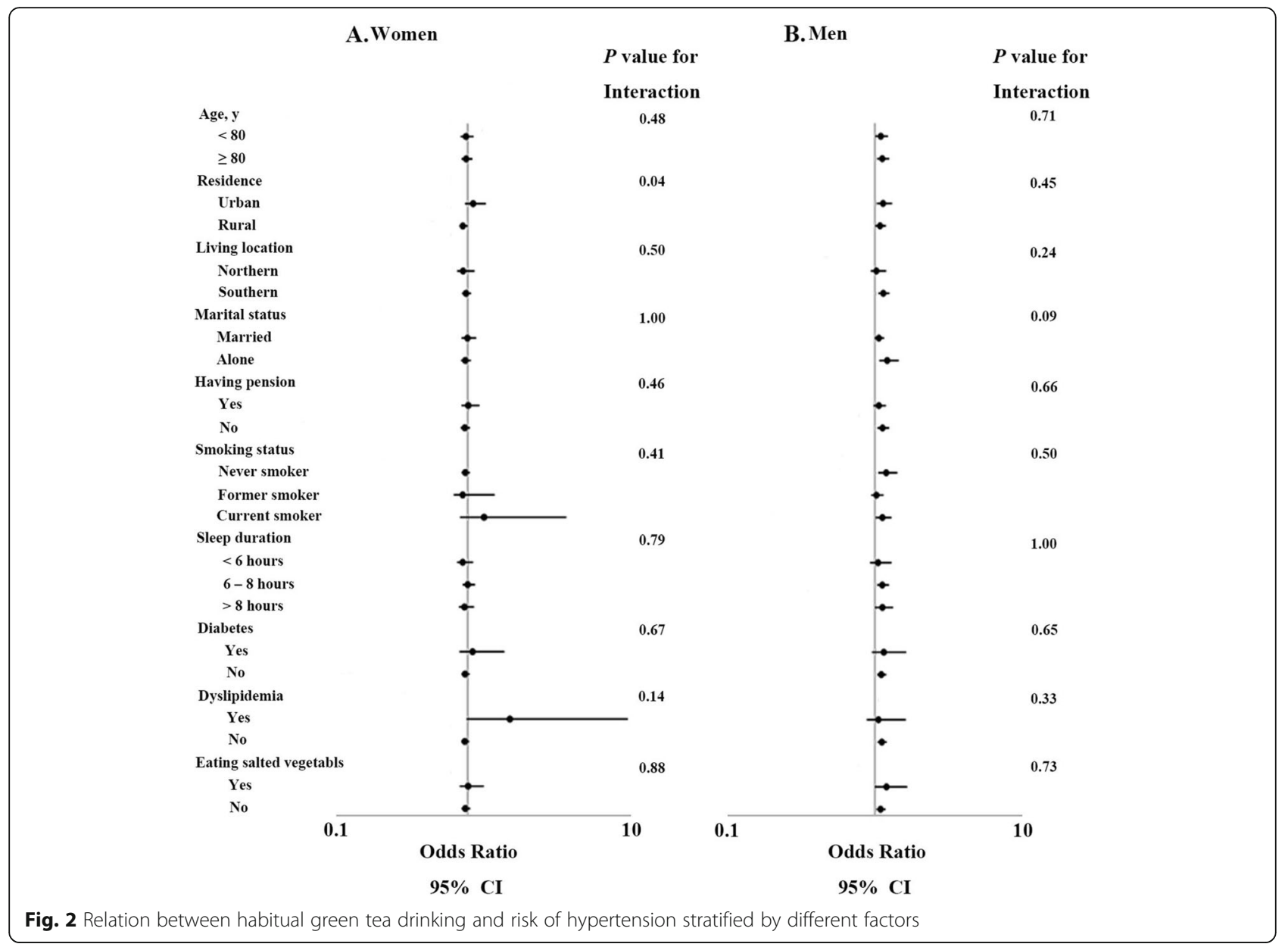

represent individuals who are more likely to be longevous.

Notably, a sex difference in habitual green tea drinking and the development of hypertension was observed. Generally, estrogen is regarded as one of the most protective factors for preventing heart diseases and hypertension in women [20]. However, the advantage of sex hormones became negligible among post-menopausal women with a higher testosterone/estradiol ratio, which increases the risk of incident cardiovascular diseases [21]. In this case, the different lifestyles may contribute to the different results between women and men. Most remarkably, women were less likely to be regular alcohol users (5.2\% vs. $23.0 \%)$ or smokers $(3.3 \%$ vs. $26.3 \%)$ than men. Although alcohol intake and smoking were lower in women than in men, a greater risk of cardiovascular diseases could be found once they started drinking and smoking [22-24]. However, the underlying mechanisms are not well understood, and further sex-specific studies are warranted.

\section{Strengths and limitations}

Two strengths of this study should be emphasized. First, the participants enrolled in this study were from the
CLHLS database, which is a well-designed program taking the longevous of age $>80$ years as the target population, with the participants distributed throughout 23 provinces in China. Second, there have been limited studies on the effect of green tea drinking on the risk of hypertension in Chinese longevous individuals, and the sex difference in this effect. The major limitations were as follows: (1) the data were extracted from a public database, which was not specifically designed to investigate the topic of interest; therefore, some important information, such as the educational level of participants, may be missing or unavailable; (2) the details of the daily green tea intake and the type of green tea were not designed within the questionnaire, limiting further analysis; and (3) the diagnosis of hypertension was self-reported and no medical records were available.

\section{Conclusions}

Green tea consumption was associated with a $38 \%$ increase in the risk of hypertension in Chinese longevous men. However, no effect of green tea consumption on the incidence of hypertension in women was found. More attention should be paid to health promotion to 
improve the lifestyle of the elderly population in China. Further sex-specific investigations are needed to identify the underlying mechanisms of the observed differences.

\section{Acknowledgements}

We thank Yaping Dong for her support.

\section{Authors' contributions}

XP performed the statistical analyses and wrote the manuscript; MZ, XW, and KW collected the data of interest; $Y L$, LL, and JY participated in manuscript preparation; $\mathrm{YR}, \mathrm{RB}$, and $\mathrm{CM}$ reviewed the manuscript before publication; and $\mathrm{NL}$ designed the study protocol. All authors confirmed that they have read and approved the manuscript and have met the criteria for authorship.

\section{Funding}

This work was supported by the National Science Foundation of China (Grant Nos. 81870244 and 81770318)

\section{Availability of data and materials}

The CLHLS questionnaires are available at https://sites.duke.edu/ centerforaging/ programs/chinese-longitudinal-healthy-longevity-surveyclhls/ survey-documentation/questionnaires/. The full datasets used in this analysis are available from the corresponding author upon reasonable request.

\section{Declarations}

\section{Ethics approval and consent to participate}

The CLHLS study was approved by the Research Ethics Committee of Peking University (IRB00001052-13074), and all participants provided written informed consent. All methods were performed in accordance with the relevant guidelines and regulations (e.g., the Declaration of Helsinki).

\section{Consent for publication}

Not applicable.

\section{Competing interests}

The authors declare that they have no competing interests.

\section{Author details}

'Department of Cardiology, Beijing Anzhen Hospital, Capital Medical University, Beijing, China. ${ }^{2}$ National Clinical Research Center for Cardiovascular Diseases, Beijing, China. ${ }^{3}$ Department of Cardiology, Beijing ChuiYangLiu Hospital, Beijing, China.

\section{Received: 11 March 2021 Accepted: 30 August 2021}

Published online: 07 September 2021

\section{References}

1. Mahdavi-Roshan M, Salari A, Ghorbani Z, Ashouri A. The effects of regular consumption of green or black tea beverage on blood pressure in those with elevated blood pressure or hypertension: a systematic review and meta-analysis. Comp Ther Med. 2020. https://doi.org/10.1016/j.ctim.2020.1 02430.

2. Bogdanski P, Suliburska J, Szulinska M, Stepien M, Pupek-Musialik D, Jablecka A. Green tea extract reduces blood pressure, inflammatory biomarkers, and oxidative stress and improves parameters associated with insulin resistance in obese, hypertensive patients. Nutr Res. 2012;32(6):421-7. https://doi.org/1 0.1016/j.nutres.2012.05.007

3. Malekzadeh MM, Etemadi A, Kamangar F, Khademi H, Golozar A, Islami F, et al. Prevalence, awareness and risk factors of hypertension in a large cohort of Iranian adult population. J Hypertens. 2013;31(7):1364-71. https:// doi.org/10.1097/HJH.0b013e3283613053.

4. Roerecke M, Tobe SW, Kaczorowski J, Bacon SL, Vafaei A, Hasan OS, et al. Sex-specific associations between alcohol consumption and incidence of hypertension: a systematic review and meta-analysis of cohort studies. J Am Heart Assoc. 2018;7(13):e008202.

5. Beale AL, Meyer P, Marwick TH, Lam CS, Kaye DM. Sex differences in cardiovascular pathophysiology: why women are overrepresented in heart failure with preserved ejection fraction. Circulation. 2018;138(2):198-205. https://doi.org/10.1161/CIRCULATIONAHA.118.034271.
6. Haider A, Bengs S, Luu J, Osto E, Siller-Matula JM, Muka T, et al. Sex and gender in cardiovascular medicine: presentation and outcomes of acute coronary syndrome. Eur Heart J. 2020;41(13):1328-36. https://doi.org/10.1 093/eurheartj/ehz898.

7. Arnold AP, Cassis LA, Eghbali M, Reue K, Sandberg K. Sex hormones and sex chromosomes cause sex differences in the development of cardiovascular diseases. Arterioscler Thromb Vasc Biol. 2017;37(5):746-56. https://doi.org/1 0.1161/ATVBAHA.116.307301.

8. Choi HM, Kim HC, Kang DR. Sex differences in hypertension prevalence and control: analysis of the 2010-2014 Korea National Health and nutrition examination survey. PLoS One. 2017;12(5):e0178334. https://doi.org/10.1371/ journal.pone.0178334.

9. Yi Z. Reliability of age reporting among the Chinese oldest-old in the CLHLS datasets. In: Healthy longevity in China: Springer, Dordrecht; 2008. p. 61-78.

10. Von Elm E, Altman DG, Egger M, Pocock SJ, Gøtzsche PC, Vandenbroucke $J P$. The strengthening the reporting of observational studies in epidemiology (STROBE) statement: guidelines for reporting observational studies. Ann Intern Med. 2007;147(8):573-7. https://doi.org/10.7326/0003-4 819-147-8-200710160-00010

11. Leng B, Jin Y, Li G, Chen L, Jin N. Socioeconomic status and hypertension: a meta-analysis. J Hypertens. 2015;33(2):221-9. https://doi.org/10.1097/HJH. 0000000000000428

12. Crump C, Sundquist J, Winkleby MA, Sundquist K. Interactive effects of physical fitness and body mass index on the risk of hypertension. JAMA Intern Med. 2016;176(2):210-6. https://doi.org/10.1001/jamainternmed.2015. 7444

13. Spitzer RL, Kroenke K, Williams JB, Löwe B. A brief measure for assessing generalized anxiety disorder: the GAD-7. Arch Intern Med. 2006;166(10): 1092-7. https://doi.org/10.1001/archinte.166.10.1092.

14. Yang Y-C, Lu F-H, Wu J-S, Wu C-H, Chang C-J. The protective effect of habitual tea consumption on hypertension. Arch Intern Med. 2004;164(14): 1534-40. https://doi.org/10.1001/archinte.164.14.1534.

15. Li W, Yang J, Zhu X, Li S, Ho P. Correlation between tea consumption and prevalence of hypertension among Singaporean Chinese residents aged $\geqslant 40$ years. J Hum Hypertens. 2016;30(1):11-7. https://doi.org/10.1038/jhh.2015.45.

16. Chei C-L, Loh JK, Soh A, Yuan J-M, Koh W-P. Coffee, tea, caffeine, and risk of hypertension: the Singapore Chinese health study. Eur J Nutr. 2018:57(4): 1333-42. https://doi.org/10.1007/s00394-017-1412-4.

17. Hügel HM, Jackson N, May B, Zhang AL, Xue CC. Polyphenol protection and treatment of hypertension. Phytomedicine. 2016;23(2):220-31. https://doi. org/10.1016/j.phymed.2015.12.012.

18. Temple JL, Bernard C, Lipshultz SE, Czachor JD, Westphal JA, Mestre MA. The safety of ingested caffeine: a comprehensive review. Front Psychiatry. 2017:8:80. https://doi.org/10.3389/fpsyt.2017.00080.

19. Bromfield SG, Bowling CB, Tanner RM, Peralta CA, Odden MC, Oparil S, et al. Trends in hypertension prevalence, awareness, treatment, and control among US adults 80 years and older, 1988-2010. J Clin Hypertens. 2014; 16(4):270-6. https://doi.org/10.1111/jch.12281.

20. Colafella KMM, Denton KM. Sex-specific differences in hypertension and associated cardiovascular disease. Nat Rev Nephrol. 2018;14(3):185-201. https://doi.org/10.1038/nrneph.2017.189.

21. Zhao D, Guallar E, Ouyang P, Subramanya V, Vaidya D, Ndumele CE, et al. Endogenous sex hormones and incident cardiovascular disease in postmenopausal women. J Am Coll Cardiol. 2018;71(22):2555-66. https://doi. org/10.1016/j.jacc.2018.01.083.

22. Zheng Y-L, Lian F, Shi Q, Zhang C, Chen Y-W, Zhou Y-H, et al. Alcohol intake and associated risk of major cardiovascular outcomes in women compared with men: a systematic review and meta-analysis of prospective observational studies. BMC Public Health. 2015;15(1):1-11.

23. Bell S, Daskalopoulou M, Rapsomaniki E, George J, Britton A, Bobak M, et al. Association between clinically recorded alcohol consumption and initial presentation of 12 cardiovascular diseases: population based cohort study using linked health records. BMJ. 2017;356:j909.

24. Huxley RR, Woodward M. Cigarette smoking as a risk factor for coronary heart disease in women compared with men: a systematic review and meta-analysis of prospective cohort studies. Lancet. 2011;378(9799):1297305. https://doi.org/10.1016/S0140-6736(11)60781-2.

\section{Publisher's Note}

Springer Nature remains neutral with regard to jurisdictional claims in published maps and institutional affiliations. 